\title{
Anthropometric, lifestyle and parental characteristics associated with the prevalence of energy intake misreporting in children: the GRECO (Greek Childhood Obesity) study
}

\author{
Paul Farajian ${ }^{1}$, Vassiliki Bountziouka ${ }^{2}$, Grigoris Risvas ${ }^{1}$, Demosthenes B. Panagiotakos ${ }^{2}$ \\ and Antonis Zampelas ${ }^{1,3 *}$ \\ ${ }^{1}$ Unit of Human Nutrition, Department of Food Science and Human Nutrition, Agricultural University of Athens, \\ 75 Street Iera Odos, 11855 Athens, Greece \\ ${ }^{2}$ Department of Nutrition-Dietetics, Harokopio University, 70 Street Eleftheriou Venizelou, 17671 Athens, Greece \\ ${ }^{3}$ Department of Nutrition and Health, United Arab Emirates University, 15551 Al Ain, United Arab Emirates
}

(Submitted 8 February 2014 - Final revision received 5 January 2015 - Accepted 21 January 2015 - First published online 18 March 2015)

\section{Abstract}

The objectives of the present study were to identify childhood energy misreporting, and evaluate characteristics that are associated with its prevalence in a nationwide cross-sectional sample of Greek schoolchildren. Under the context of the GRECO (Greek Childhood Obesity) study, data from a total of 4547 children aged 10-12 years and 2318 parents were included in the analysis. Anthropometric, lifestyle and parental characteristics plus psychological concerns were investigated in relation to the prevalence of energy misreporting. Of the included children, 36\% were classified as energy under-reporters and $16 \%$ as over-reporters. Multinomial logistic regression analysis revealed that the most important predictors of energy under-reporting (URP) were children's BMI (OR 1.11, 95\% CI 1.09, 1.14) and weight satisfaction (OR $0 \cdot 87,95 \% \mathrm{CI} 0 \cdot 78,0 \cdot 97)$. In the case of energy over-reporting (ORP), children's BMI (OR 0.87, 95\% CI 0.84, 0.90), meal and snack consumption frequency (OR 1.52, $95 \%$ CI 1.32, 1.75), female sex (OR 0.65, 95\% CI 0.45, 0.90), and maternal education (OR 0.95, 95\% CI 0.91, 0.99) remained as significant predictors. Additionally, parental perception that the body weight of their children was normal reduced the odds of URP (OR 0.69, $95 \%$ CI 0.48, 0.99) and ORP (OR 0.53, 95\% CI 0.31, 0.93). In conclusion, the present study confirms that the issue of URP and ORP in childhood populations is evident and quite serious. Although there are no definite guidelines on how to use data obtained from misreporters in an epidemiological dataset, validity of reported energy intake seems to be influenced by children's BMI and weight satisfaction, as well as by parental perceptions regarding their children's weight.

Key words: Under-reporting: Over-reporting: Children: Parental perceptions

Accuracy of dietary assessment is essential in nutritional research, where associations between diet and health or disease are investigated. Habitual intakes of foods and consequently nutrients are often assessed by self-reported methods depending on the design of the studies ${ }^{(1)}$. Although it is generally recognised that obtaining accurate dietary data is difficult due to misreporting of dietary intake, diet-disease associations are established on the assumption that reported dietary intake is accurate and depending on the method used to reflect usual intake ${ }^{(2)}$. Involuntary measurement errors due to subjects' difficulties in remembering the foods consumed, food recognition, portion size and estimation of consumption frequency may influence reporting accuracy in dietary surveys. More importantly, research mostly focused on adults has indicated that biased (systematic) dietary misreporting is also often observed. Biased misreporting has been reported for energy-dense, nutrient-poor foods perceived as unhealthy, as well as in subcategories of the population influenced by psychological concerns such as body image and weight dissatisfaction, with the need of social approval and desirability, and restrained eating ${ }^{(3,4)}$. Thus, when systematic rather than random errors occur, they lead to significant reporting errors that may attenuate or exaggerate the associations between dietary factors and health outcomes, or even change the direction of these associations ${ }^{(5,6)}$.

According to recent validation studies, misreporting of energy intake (EI) is quite evident in children and adolescents as well, with rates of under-reporting (URP) increasing with age and body-weight status ${ }^{(4)}$. Depending on the assessment tool used, the prevalence of URP has been reported to vary

Abbreviations: EI, energy intake; GRECO, Greek Childhood Obesity; ORP, over-reporting; PAL, physical activity level; URP, under-reporting. 
from 2 to $85 \%$, while the prevalence of over-reporting (ORP) varies from 3 to $46 \%{ }^{(7)}$. Although some characteristics (i.e. sociodemographic, eating behaviours, body image, lifestyle and physical activity) and their associations with URP have been previously studied, these reporting biases from habitual eating patterns are not fully studied, especially among children, while data regarding ORP are even more limited ${ }^{(8)}$.

Thus, the objectives of the present study were to identify children misreporters (under- and over-reporters), evaluate anthropometric, lifestyle and parental characteristics that are associated with the prevalence of energy misreporting, and assess perceptional parameters that are associated with URP and ORP, in a nationwide cross-sectional sample of Greek schoolchildren (the GRECO (Greek Childhood Obesity) study).

\section{Experimental methods}

\section{Study sample}

The study was carried out from October to May 2009 under the context of the GRECO study ${ }^{(9)}$. A stratified sampling scheme, weighted by age, sex group and region according to the population distribution (National Statistical Services, 2001 census) in all ten regions of the whole country (i.e. Attica, Macedonia, Peloponnisos, Sterea Ellada and Evia, Ipeiros, Thessalia, Thrace, Aegean Islands, Ionian Islands and Crete), was used to obtain a representative sample of 5000 children. The number of children to be enrolled in each region was proportional to the total population of the region. This number had been pre-specified using statistical power calculations in order to achieve $85 \%$ power at $5 \%$ type I error with the OR of $1 \cdot 10$. Using the official catalogues provided by the regional directorates of primary education, a total of 5850 fifth- and sixth-grade schoolchildren from fourteen prefectures were randomly invited for potential inclusion from 130 selected public primary schools. From all over the country (ten regions and fourteen prefectures), the number of schools that agreed to participate in the study was 117 . From the overall number of children who were invited to participate in the study, signed parental consent forms were obtained for 4965 children (84.9\% participation rate). After checking the completeness of the provided data, the working sample of the present study included 4547 voluntarily enrolled fifth- and sixth-grade schoolchildren with a mean age of 10.9 ( $\mathrm{sD} 0.75)$ years $(49.3 \%$ male). The studied sample could be considered as representative of the overall study population (i.e. the children included for analysis in the GRECO study) according to age, sex, BMI and regional distributions, as differences were not evident between the present and the overall GRECO samples ${ }^{(9)}(P>0.05)$. The present study was conducted according to the guidelines laid down in the Declaration of Helsinki. The research tools and all the means used in the study were approved by the Hellenic Ministry of Education (Department of Primary Education) as the law provides in Greece for any studies conducted in the school environment during formal school hours, and the Agricultural University of Athens Research Committee. Written informed consent was obtained from all subjects.

\section{Anthropometric characteristics}

Body weight (kg) was measured to the nearest $100 \mathrm{~g}$ using a digital scale (Tanita TBF 300). Height was measured using a portable stadiometer (Leicester Height Measure) to the nearest $0 \cdot 1 \mathrm{~cm}$ without shoes. BMI was calculated by dividing weight $(\mathrm{kg})$ by height squared $\left(\mathrm{m}^{2}\right)$. Obesity and overweight among children were calculated using the IOTF (International Obesity Task Force) age- and sex-specific BMI cut-off criteria ${ }^{(10)}$. Waist and hip circumferences were measured to the nearest $0 \cdot 1 \mathrm{~cm}$ using a non-elastic tape (Seca). Waist circumference was measured at the end of a gentle expiration after placing the measuring tape in a horizontal plane around the trunk, at the midway between the lower rib margin and the iliac crest. Hip circumference was measured at the point yielding the maximum circumference over the buttocks. The waist:hip ratio was also calculated. Percentage of body fat and body fat mass were estimated by the foot-to-foot impedance method (Tanita TBF 300). All measurements were performed during morning hours.

\section{Dietary and eating behaviour assessment}

Dietary assessment was based on a validated self-reported, semi-quantitative picture-aid FFQ consisting of forty-eight food items commonly used in the local Greek cuisine ${ }^{(11,12)}$. All participants were asked about their usual frequency of consumption of food items (average over the last year) with the following response categories: every day; 3-6 times/week; 2 times/week; 1 time/week; 1-2 times/month; seldom/ never. Pictures regarding the standard portion size of each food item included in the questionnaire to assist children in reporting the exact food quantity consumed. The questionnaire included supplementary questions assessing the frequency of breakfast consumption and eating occasions (number of meals and snacks consumed during the day), as well as the type of the foods consumed (i.e. consumption of (1) whole-wheat products (cereals, pasta, bread, cereal bars and rusks), (2) brown rice, (3) low-fat milk and yogurt, (4) low-fat mayonnaise and (5) light soft drinks). To estimate daily EI, the United States Department of Agriculture food composition tables ${ }^{(13)}$ and the local food composition tables $^{(14)}$ were used.

\section{Other characteristics}

All participants were asked to complete the Physical Activity Questionnaire for Older Children ${ }^{(15)}$. Children were also asked to report the time spent on watching television and recreational usage of games consoles/computer during weekdays and weekends (h/d). By combining the former two responses, mean daily hours of watching television/DVD/movies and/or recreational usage of game consoles/computer (defined as screen time) were calculated. Responses were coded into two categories $(<2$ and $\geq 2 \mathrm{~h} / \mathrm{d})$ of low- and high-sedentary lifestyles. Additionally, children were asked to report how content they felt about their body weight using a 5-point scale (1 (not at all)-5 (very content)), and to consider and 
report their weight. The former question was applied before the actual body-weight measurement. Based on this information, the deviation between the actual measured weight value and the perceived weight was calculated.

\section{Classification of misreporting}

Energy misreporting (i.e. URP and ORP) was estimated using the Goldberg equation ${ }^{(16)}$ according to the ratio of EI:BMR. In particular, age-specific Schofield's equations were used to estimate BMR from measured weight ${ }^{(17)}$. The Physical Activity Questionnaire $^{(15)}$ that we used for the assessment of physical activity levels (PAL) has no definitive cut-offs for PAL classification, and therefore we could not group children into categories of activity. Therefore, PAL was set to 1.55 , assuming moderate activity levels. Since the FFQ used in the present study measured usual food intake during the past year, the evaluation of individual food intake by habitual dietary assessment methods (e.g. FFQ and diet history) was based on $28 \mathrm{~d}$, which is the maximum duration of dietary assessment as suggested by Goldberg et al. ${ }^{(18)}$. The within-subject daily variation in $\mathrm{EI}\left(\mathrm{CV}_{\mathrm{wE}}\right)$, the variation in $\mathrm{BMR}\left(\mathrm{CV}_{\mathrm{wB}}\right)$ and the between-subject variation in physical activity $\left(\mathrm{CV}_{\mathrm{tP}}\right)$ were set at suitable average values of $23,8.5$ and $15 \%$, respectively ${ }^{(16)}$. According to these criteria, under-reporters of EI were defined as those with an EI:BMR ratio of $<1.09$, while over-reporters of EI were those with an EI:BMR ratio of $>2 \cdot 21$.

\section{Parental characteristics}

Information on socio-economic and sociodemographic characteristics such as parents' age, years of education, type of occupation (manual workers (lower values) to executive/ skilled workers (higher values)) was collected via a questionnaire that was attached with the consent form. Parents were also asked about the frequency of physical activity alone or together with their children (i.e. 1 time/week, 2-3 times/ week, $4-5$ times/week and $\geq 6$ times/week), as well as the frequency of meals consumed with the whole family and the frequency of meals consumed 'out of home'. Of the total consent forms obtained, 2318 answered parental questionnaires ( $51 \%$ participation rate) were also collected. Percentages of parental obesity and overweight were also estimated from self-reported values of body weight and height. According to the WHO classification ${ }^{(19)}$, BMI measures were used to define adult (parental) obesity (BMI $\geq 30 \mathrm{~kg} / \mathrm{m}^{2}$ ) and overweight (BMI $25 \cdot 0-29 \cdot 9 \mathrm{~kg} / \mathrm{m}^{2}$ ).

Parents were also asked to report their perspective about the body weight of their children (i.e. lower than normal, normal and higher than normal), and to evaluate their children's quality of diet using a 10-grade scale ( $1=$ low quality/ unhealthy; $10=$ high quality/healthy). Parental dietary habits and practices were assessed by the Mediterranean Diet Score (range 0-55) in order to evaluate their adherence to the Mediterranean diet (with higher values indicating high adherence to the scheme $)^{(20)}$.

\section{Statistical analyses}

Results are presented as means and standard deviations for normally distributed continuous variables, medians and 25th-75th percentiles for skewed variables and frequencies (\%) for categorical variables. Normality was tested by using graphical methods (i.e. histograms and $\mathrm{P}-\mathrm{P}$ plots) and homogeneity of variance by Levene's test. Differences in the distribution of continuous variables between the three categories of EI reporters (i.e. under-, plausible and over-reporters) were assessed using the one-way ANOVA $F$ test for normally distributed variables, with the Bonferroni rule to correct for the inflation of type I error resulting from multiple comparisons. According to the Bonferroni rule, the $P$ value of each individual test was multiplied by the number of post hoc analyses. The associations between skewed variables and groups of participants were evaluated by the Kruskal-Wallis $H$ test. The associations between categorical variables were analysed using the $\chi^{2}$ test. Furthermore, unadjusted and multinomial logistic regression analyses were used to evaluate the main effect of several parental and children's characteristics on the prevalence of childhood energy misreporting. Variables included into the model of multinomial logistic regression analysis were selected according to the results of unadjusted models (i.e. $P<0.05)$ and as such to avoid collinearity. Results are presented as OR and $95 \% \mathrm{CI}$. All reported $P$ values were based on a two-sided test hypothesis and compared with a significance level of 5\%. All statistical analyses were performed using SPSS software version 18.0 (SPSS, Inc.).

\section{Results}

Among the participating children, 36\% were classified as under-reporters and $16 \%$ as over-reporters. Children's anthropometric, dietary and lifestyle characteristics according to their classification of EI reporting (i.e. under-, plausible and overreporters) are presented in Table 1. Boys were more frequently ORP and less frequently URP their EI than girls. Differences were evident in relation to body weight, bodyweight perception and satisfaction, BMI, percentage of body fat, waist and hip circumferences, waist:height ratio, prevalence of overweight/obesity, and prevalence of children spending more than $2 \mathrm{~h} / \mathrm{d}$ in front of a screen. Differences in EI and dietary habits according to children's classification were evident between the groups since under-reporters consumed breakfast less frequently than the rest of the two groups, while daily consumption frequency of meals and snacks was different between the three groups (all $P<0.001)$. In addition, over-reporters compared with underreporters consumed more frequently whole-wheat pasta $(P<0.001)$ and whole-wheat bread $(P=0.006)$, while no differences were observed with regard to the consumption of whole-wheat cereals, cereal bars, brown rice and wholewheat rusks between the three groups. On the contrary, under-reporters when compared with over-reporters more frequently consumed low-fat milk, yogurt and cheese (all $P<0.001$ ), but not light soft drinks or mayonnaise (data not shown). 
Table 1. Children's anthropometric, dietary and lifestyle characteristics according to their classification of energy intake (EI) reporting (Mean values* and standard deviations; median values† and 25th-75th percentiles; frequencies and percentages $\ddagger$ )

\begin{tabular}{|c|c|c|c|c|c|c|c|c|}
\hline & \multirow[b]{3}{*}{$n$} & \multicolumn{7}{|c|}{ El reporters } \\
\hline & & \multicolumn{2}{|c|}{ Under-reporters } & \multicolumn{2}{|c|}{ Plausible reporters } & \multicolumn{2}{|c|}{ Over-reporters } & \multirow[b]{2}{*}{$P \S$} \\
\hline & & Mean & SD & Mean & SD & Mean & SD & \\
\hline$\%$ & 4547 & \multicolumn{2}{|c|}{36} & \multicolumn{2}{|c|}{48} & \multicolumn{2}{|c|}{16} & \\
\hline Age (years) & 4547 & $11 \cdot 0$ & 0.72 & $11 \cdot 0$ & 0.73 & $11 \cdot 0$ & 0.74 & 0.15 \\
\hline Boys (\%) & 4547 & \multicolumn{2}{|c|}{47} & \multicolumn{2}{|c|}{48} & \multicolumn{2}{|c|}{55} & 0.002 \\
\hline Body weight (kg) & 4547 & \multirow{2}{*}{\multicolumn{2}{|c|}{50}} & \multirow{2}{*}{\multicolumn{2}{|c|}{10}} & \multirow{2}{*}{\multicolumn{2}{|c|}{$8 \cdot 7$}} & $<0.001$ \\
\hline $\begin{array}{l}\text { Deviance between the actual measured body } \\
\text { weight and the perceived body weight }(\mathrm{kg})\end{array}$ & 4378 & & & & & & & $<0.001$ \\
\hline Median & & \multirow{2}{*}{\multicolumn{2}{|c|}{$\begin{array}{c}0.90 \\
-0.5,3.0\end{array}$}} & \multirow{2}{*}{\multicolumn{2}{|c|}{$\begin{array}{c}0.40 \\
-0.8 .2 .3\end{array}$}} & \multirow{2}{*}{\multicolumn{2}{|c|}{$\begin{array}{c}0.00 \\
-1.3,1.5\end{array}$}} & \\
\hline 25th-75th percentile & & & & & & & & \\
\hline BMI $\left(\mathrm{kg} / \mathrm{m}^{2}\right)$ & 4523 & $22 \cdot 0$ & $4 \cdot 0$ & $20 \cdot 0$ & 3.6 & $19 \cdot 0$ & $3 \cdot 8$ & $<0.001$ \\
\hline Percentage of body fat & 4485 & 24.0 & $9 \cdot 0$ & $20 \cdot 0$ & 8.5 & $17 \cdot 0$ & $7 \cdot 7$ & $<0.001$ \\
\hline Waist circumference (cm) & 4508 & $71 \cdot 0$ & 9.9 & $68 \cdot 0$ & $9 \cdot 3$ & $65 \cdot 0$ & $8 \cdot 2$ & $<0.001$ \\
\hline Hip circumference $(\mathrm{cm})$ & 4496 & $86 \cdot 0$ & $10 \cdot 0$ & 82 & $9 \cdot 7$ & 79 & 8.8 & $<0.001$ \\
\hline Waist:hip ratio & 4487 & 0.83 & 0.07 & 0.83 & 0.08 & 0.83 & 0.07 & 0.51 \\
\hline Waist:height ratio $(\mathrm{cm})$ & 4487 & 0.47 & 0.06 & 0.45 & 0.06 & 0.44 & 0.05 & $<0.001$ \\
\hline Prevalence of overweight/obesity (\%) & 4523 & \multicolumn{2}{|c|}{55} & \multicolumn{2}{|c|}{37} & \multicolumn{2}{|c|}{21} & $<0.001$ \\
\hline PAQ-C score (1-5) & 4445 & $2 \cdot 9$ & 0.59 & 3.0 & 0.61 & 3.0 & 0.62 & 0.20 \\
\hline Screen time $\geq 2 \mathrm{~h} / \mathrm{d}(\%)$ & 4282 & \multicolumn{2}{|c|}{$46 \cdot 3$} & \multicolumn{2}{|c|}{$45 \cdot 6$} & \multicolumn{2}{|c|}{$51 \cdot 4$} & 0.029 \\
\hline \multicolumn{9}{|l|}{$\mathrm{EI}(\mathrm{kJ} / \mathrm{d})$} \\
\hline Boys & 2242 & 5050 & 1309 & 9418 & 2105 & 15610 & 2460 & $<0.001$ \\
\hline Girls & 2305 & 4531 & 1058 & 8180 & 1770 & 14175 & 2540 & $<0.001$ \\
\hline Weekly consumption of breakfast & 4298 & $4 \cdot 2$ & $2 \cdot 5$ & 4.6 & $2 \cdot 4$ & 4.6 & $2 \cdot 4$ & $<0.001$ \\
\hline Daily meal and snack consumption frequency & 4379 & $2 \cdot 9$ & $1 \cdot 2$ & $3 \cdot 2$ & $1 \cdot 2$ & 3.5 & 1.3 & $<0.001$ \\
\hline $\begin{array}{l}\text { How content you are with your body weight (\%) } \\
(1 \text { (not at all) }-5 \text { (very content)) }\end{array}$ & 4226 & & & & & & & $<0.001$ \\
\hline 1 & & \multicolumn{2}{|c|}{$17 \cdot 4$} & \multicolumn{2}{|c|}{$11 \cdot 2$} & \multicolumn{2}{|c|}{$10 \cdot 5$} & \\
\hline 2 & & \multirow{2}{*}{\multicolumn{2}{|c|}{$\begin{array}{l}18.5 \\
27.9\end{array}$}} & \multirow{2}{*}{\multicolumn{2}{|c|}{$\begin{array}{l}12 \cdot 3 \\
27 \cdot 3\end{array}$}} & & & \\
\hline 3 & & & & & & & & \\
\hline 4 & & & & & & & & \\
\hline 5 & & & & & & & & \\
\hline
\end{tabular}

PAQ-C, Physical Activity Questionnaire for Older Children.

${ }^{*}$ For normally distributed continuous variables.

†For skewed variables.

$\ddagger$ For categorical variables.

$\S P$ values were derived by comparisons between the three categories of El reporters using one-way ANOVA for normally distributed variables, Kruskal-Wallis $H$ test for skewed variables and Pearson's $\chi^{2}$ test for categorical variables.

With respect to parental characteristics, mothers of overreporters tended to be less educated ( $P=0 \cdot 01$; Table 2$)$. In addition, fathers' type of occupation differed between the three groups of EI reporters (all $P<0 \cdot 01$ ), while mothers' type of occupation was more manual for over-reporters than for plausible reporters. Mothers of under-reporters had higher BMI than those of normal $(P<0.05)$ and over-reporters $(P=0.003)$. In the case of over-reporters, having one parent overweight/obese was more frequent, while for underreporters, having both parents overweight/obese was more probable. The percentage of parents considering that their children's body weight was higher than normal was higher among under-reporters, whereas the proportion of parents considering that their children's body weight was lower than normal was higher among over-reporters (all $P<0 \cdot 001$ ). Parents' perception regarding their children's quality of diet was higher for over-reporters, followed by plausible reporters and under-reporters (all $P<0 \cdot 001$ ). Additionally, underreporters had rarely family meals, while over-reporters had more frequent family meals.

The effects of selected children's and parents' anthropometric and lifestyle characteristics, as well as perceptions on the likelihood of misreporting, as revealed by the multinomial regression analysis, are presented in Table 3 . In the case of URP, the analysis showed that children's higher BMI was associated with a higher likelihood of URP. In addition, higher satisfaction of children with their body weight decreased the likelihood of URP, and the same effect was observed for parental perception that their children had a normal body weight. In the case of ORP, children's higher BMI, female sex, higher maternal education and parental perception that their children had a normal body weight decreased the likelihood of a child to be categorised as an over-reporter. Conversely, increased frequency of meals and snacks consumed during the day was associated with a higher likelihood of being categorised as an over-reporter.

\section{Discussion}

Under the context of the GRECO study, insight is provided into the issue of energy misreporting in children, in relation to anthropometric, adiposity (body fat measurement), food preferences, sociodemographic and perceptional (individual as well as parental) parameters that appear to be associated 
Table 2. Parents' sociodemographic, anthropometric and lifestyle characteristics according to energy intake reporting of their children (Mean values* and standard deviations; frequenciest)

\begin{tabular}{|c|c|c|c|c|c|c|c|c|}
\hline & \multirow[b]{3}{*}{$n$} & \multicolumn{7}{|c|}{ Energy intake reporters } \\
\hline & & \multicolumn{2}{|c|}{$\begin{array}{l}\text { Under- } \\
\text { reporters }\end{array}$} & \multicolumn{2}{|c|}{$\begin{array}{l}\text { Plausible } \\
\text { reporters }\end{array}$} & \multicolumn{2}{|c|}{$\begin{array}{l}\text { Over- } \\
\text { reporters }\end{array}$} & \multirow[b]{2}{*}{$P \ddagger$} \\
\hline & & Mean & SD & Mean & SD & Mean & SD & \\
\hline Fathers' age (years) & 2015 & $44 \cdot 2$ & $5 \cdot 2$ & 44.5 & $5 \cdot 7$ & $43 \cdot 5$ & $5 \cdot 6$ & 0.021 \\
\hline Mothers' age (years) & 2051 & $39 \cdot 8$ & 4.5 & $39 \cdot 8$ & $4 \cdot 7$ & $39 \cdot 0$ & 4.9 & 0.008 \\
\hline Paternal education (years) & 1795 & $13 \cdot 0$ & $4 \cdot 1$ & $13 \cdot 0$ & $4 \cdot 2$ & $13 \cdot 0$ & $4 \cdot 3$ & 0.06 \\
\hline Maternal education (years) & 1845 & $14 \cdot 0$ & 3.5 & $14 \cdot 0$ & 3.7 & $13 \cdot 0$ & $3 \cdot 8$ & 0.01 \\
\hline Fathers' BMI $\left(\mathrm{kg} / \mathrm{m}^{2}\right)$ & 1815 & 28.0 & 3.4 & $27 \cdot 0$ & 3.6 & $27 \cdot 0$ & 3.7 & 0.23 \\
\hline Mothers' BMI $\left(\mathrm{kg} / \mathrm{m}^{2}\right)$ & 1917 & $25 \cdot 0$ & $4 \cdot 2$ & $24 \cdot 0$ & 3.7 & $24 \cdot 0$ & 4.4 & 0.003 \\
\hline Fathers' type of occupation (1 (manual) -10 (non-manual)) & 1817 & $5 \cdot 8$ & $2 \cdot 8$ & $6 \cdot 2$ & $2 \cdot 7$ & $5 \cdot 6$ & $2 \cdot 8$ & 0.001 \\
\hline Mothers' type of occupation ( 1 (manual) -10 (non-manual) $)$ & 1719 & $6 \cdot 3$ & $2 \cdot 7$ & $6 \cdot 5$ & $2 \cdot 8$ & $6 \cdot 0$ & $2 \cdot 9$ & 0.04 \\
\hline Parents' obesity status (\%) & 1766 & & & & & & & 0.02 \\
\hline Neither parent overweight/obese & & \multicolumn{2}{|c|}{$15 \cdot 7$} & \multicolumn{2}{|c|}{$19 \cdot 1$} & \multicolumn{2}{|c|}{21.4} & \\
\hline One parent overweight/obese & & \multicolumn{2}{|c|}{$52 \cdot 9$} & \multicolumn{2}{|c|}{$52 \cdot 1$} & \multicolumn{2}{|c|}{$57 \cdot 2$} & \\
\hline Both parents overweight/obese & & \multicolumn{2}{|c|}{31.4} & \multicolumn{2}{|c|}{$28 \cdot 8$} & \multicolumn{2}{|c|}{21.4} & \\
\hline MedDietScore $(0-55)$ & 1977 & $28 \cdot 0$ & $5 \cdot 7$ & $28 \cdot 0$ & $5 \cdot 6$ & $28 \cdot 0$ & $5 \cdot 9$ & 0.80 \\
\hline Frequency of parents' physical activity with children (\%) & 1227 & & & & & & & 0.70 \\
\hline 1 time/week & & \multicolumn{2}{|c|}{41.0} & \multicolumn{2}{|c|}{$40 \cdot 0$} & \multicolumn{2}{|c|}{$36 \cdot 0$} & \\
\hline 2-3 times/week & & \multicolumn{2}{|c|}{$43 \cdot 0$} & \multicolumn{2}{|c|}{$44 \cdot 0$} & \multicolumn{2}{|c|}{$47 \cdot 0$} & \\
\hline 4-5 times/week & & \multicolumn{2}{|c|}{$13 \cdot 0$} & \multicolumn{2}{|c|}{$14 \cdot 0$} & \multicolumn{2}{|c|}{$13 \cdot 0$} & \\
\hline$\geq 6$ times/week & & \multicolumn{2}{|c|}{$2 \cdot 1$} & \multicolumn{2}{|c|}{$3 \cdot 2$} & \multicolumn{2}{|c|}{4.4} & \\
\hline Parental perception of children's body weight (\%) & 2068 & & & & & & & $<0.001$ \\
\hline Lower than normal & & \multicolumn{2}{|c|}{$4 \cdot 1$} & \multicolumn{2}{|c|}{$7 \cdot 0$} & & & \\
\hline Normal & & 60 & & & & & & \\
\hline Higher than normal & & 35 & & & & & & \\
\hline Parental perception of children's quality of diet $(0-10)$ & 2040 & $7 \cdot 3$ & $2 \cdot 0$ & 7.5 & 1.9 & $7 \cdot 8$ & 1.9 & 0.001 \\
\hline Frequency of family meals (\%) & 2097 & & & & & & & $<0.001$ \\
\hline Never & & 1 & & & & & & \\
\hline $1-2$ times/week & & 36 & & & & & & \\
\hline 3-4 times/week & & 21 & & & & & & \\
\hline 5-6 times/week & & 8 & & & & & & \\
\hline Daily & & 32 & & & & & & \\
\hline
\end{tabular}

MedDietScore, Mediterranean Diet Score.

${ }^{*}$ For normally distributed continuous variables.

†For categorical variables.

$\ddagger P$ values were derived by comparisons between the three categories of energy intake reporters using one-way ANOVA for normally distributed variables and Pearson's $\chi^{2}$ test for categorical variables.

with the problem. Concerning the rates of energy misreporting, $36 \%$ of the children were classified as under-reporters and $16 \%$ as over-reporters. Although comparisons of the prevalence of EI misreporting between studies are difficult because of differences in the criteria used to classify underand over-reporters, dietary assessment methods and number of assessment days ${ }^{(7)}$, similar high rates of misreporting have been documented in previous studies using self-reported methods, with the problem becoming more frequent with increasing age, and especially among adolescents and $\operatorname{girls}^{(21-24)}$. Considerably, lower rates of energy misreporting have been reported in a recent study that aimed to investigate the determinants of the problem by using proxy-reported $24 \mathrm{~h}$ dietary recalls in a large sample of children ${ }^{(25)}$. According to these authors, the low proportions observed could be the consequence of the close cooperation with parents/caregivers. Taking into account the large proportion of URP and ORP observed in the present study, our findings suggest that not only URP but also ORP of EI should be considered as a serious problem in studies that include children and adolescents.

In the present study, URP was higher among girls, but ORP was more evident in boys. However, in the multinomial logistic regression analysis, sex remained as the significant predictor only in the case of ORP. The descriptive analysis used in the present study revealed that in addition to having higher body weight and BMI values, URP children also had a higher percentage of body fat mass, waist and hip circumferences, and waist:height ratio ${ }^{(23,26-28)}$. In contrast, over-reporters were less likely to be categorised as overweight/obese, had lower body weight and BMI values, as well as lower adiposity, and central or peripheral adiposity markers. These results demonstrated that not only body weight and BMI affect the accuracy of dietary energy reports, but also the body shape and particularly the degree of leanness or adiposity that affects the perceived level of fatness ${ }^{(25,29)}$. It should also be mentioned that the age of the participants is late childhood and pre-adolescence, a period of rapid growth in which boys and girls increase fat-free mass substantially, and in which girls increase body fat mass considerably ${ }^{(29)}$. Interestingly, URP children had the biggest difficulty in estimating correctly their body weight, while overreporters were much more accurate. This latter finding does not necessarily show a superior ability of ORP children, but probably a tendency of URP children to report a more desirable 
Table 3. Effects of children's and parents' sociodemographic, anthropometric and lifestyle characteristics on the prevalence of under- and over-reporting of energy intake

(Odds ratios and $95 \%$ confidence intervals*)

\begin{tabular}{|c|c|c|c|c|}
\hline & \multicolumn{4}{|c|}{ Energy reporting } \\
\hline & \multicolumn{2}{|c|}{$\begin{array}{l}\text { Under-reporters } v \text {. } \\
\text { plausible reporters }\end{array}$} & \multicolumn{2}{|c|}{$\begin{array}{l}\text { Over-reporters } v \text {. } \\
\text { plausible reporters }\end{array}$} \\
\hline & OR & $95 \% \mathrm{Cl}$ & OR & $95 \% \mathrm{Cl}$ \\
\hline \multicolumn{5}{|l|}{ Sex } \\
\hline Boys & 1 & & 1 & \\
\hline Girls & 1.14 & $0.88,1.49$ & 0.65 & $0.46,0.92$ \\
\hline Children's age (years) & 1.06 & $0.89,1.27$ & 0.79 & $0.62,1.02$ \\
\hline Children's satisfaction with body weight $(1-5)$ & 0.87 & $0.78,0.97$ & $1 \cdot 15$ & $0.98,1.35$ \\
\hline Meal and snack consumption frequency (per d) & 0.94 & $0.85,1.05$ & 1.52 & $1.32,1.75$ \\
\hline Breakfast consumption frequency (times per week) & 0.96 & $0.91,1.01$ & 0.94 & $0.87,1.00$ \\
\hline Children's BMI $\left(\mathrm{kg} / \mathrm{m}^{2}\right)$ & 1.11 & $1 \cdot 09,1 \cdot 14$ & 0.87 & $0.84,0.90$ \\
\hline Screen time $(\mathrm{h} / \mathrm{d})$ & 1.01 & $0.92,1,10$ & 1.09 & $0.97,1.22$ \\
\hline Fathers' BMI $\left(\mathrm{kg} / \mathrm{m}^{2}\right)$ & 0.97 & $0.94,1.01$ & 1.01 & $0.96,1.06$ \\
\hline Mothers' BMI $\left(\mathrm{kg} / \mathrm{m}^{2}\right)$ & 1.02 & $0.98,1.05$ & 0.98 & $0.94,1.03$ \\
\hline Maternal education (years) & 1.04 & $1.00,1.07$ & 0.95 & $0.91,0.99$ \\
\hline Parental perception of children's quality of diet $(0-10)$ & 0.98 & $0.91,1.06$ & 1.05 & $0.94,1.16$ \\
\hline \multicolumn{5}{|l|}{ Parental perception of children's body weight } \\
\hline Higher than normal & 1 & & 1 & \\
\hline Lower than normal & 0.61 & $0.30,1.21$ & 0.58 & $0.26,1.32$ \\
\hline Normal & 0.69 & $0.48,0.99$ & 0.53 & $0.31,0.93$ \\
\hline \multicolumn{5}{|l|}{ Frequency of family meals } \\
\hline 5 or more times/week & 1 & & 1 & \\
\hline Less than 5 times/week & $1 \cdot 17$ & $0.90,1.51$ & 0.81 & $0.57,1.15$ \\
\hline
\end{tabular}

* Calculated by performing multinomial logistic regression analyses.

(i.e. lower) value of body weight. As shown in Table 1, underreporters had significantly higher levels of weight concern and dissatisfaction since a higher proportion of URP children stated to be less content with their body weight. In contrast, a significantly higher proportion of ORP children were found to be satisfied with their body weight.

According to the multinomial regression analysis, when children's and parental factors were entered into one model, the factors that remained significantly associated with URP were children's BMI and weight satisfaction as well as parental perception of their children's body-weight status. Consistent with several previous reports, children with higher BMI were more likely to under-report their $\mathrm{EI}^{(23,25-28,30)}$. This finding may be associated with the tendency of URP children to deliberately omit the characteristics of their diet and report habits more consistent with perceptions of what comprises a healthy, balanced or acceptable diet, irrespective of what their actual dietary habits are. As revealed by the descriptive analysis, concerning specific food intake, URP children reported a higher preference for low-fat dairy foods (milk, yogurt and cheese), which could be assumed to be the result of selective reporting of foods that are considered to be more appropriate for maintaining weight balance or even perceived as healthier. Similarly, in the study of Börnhorst et $a{ }^{(25)}$, foods commonly perceived as unhealthy (e.g. chocolate products and soft drinks) were negatively associated with URP, while those perceived as healthy (e.g. fruit and vegetable intake) showed a positive association. Regardless of the reason, as it has been previously shown, the vast majority of children in this age group have good nutritional knowledge, and therefore they can distinguish between 'bad' or 'good' dietary choices and may adjust their answers during a dietary survey ${ }^{(31)}$. In addition, although previous studies have shown that the habit of having breakfast, and the higher number of daily meals and snacks consumed are inversely associated with the prevalence of $\operatorname{URP}^{(22,32,33)}$, the multinomial regression analysis performed in the present study showed that these parameters did not remain significantly associated. Previous findings on the association between URP and parental BMI are not consistent with those observed in children and adolescents. In the study of Börnhorst et al. ${ }^{(25)}$, parental BMI was not significantly associated with misreporting, but parental concerns/beliefs about their children's body-weight status were strongly associated with misreporting, as also confirmed in the present study.

The present data revealed a decreased risk of ORP in girls, and a significant inverse association between ORP and children's BMI. Furthermore, a positive association of ORP with daily meal and snack consumption frequency was demonstrated. Parental perception regarding their children's body-weight status (specifically perceiving it as normal) and maternal education levels were also negatively associated with the risk of ORP. Previous studies have shown conflicting results regarding the prevalence of ORP in boys and girls ${ }^{(21,26)}$. However, the negative association between BMI and ORP has been shown in other studies ${ }^{(21,25,26)}$, and may be explained by the hypothesis that children who are leaner, might want to mask what they believe or have heard to be an excessively low intake ${ }^{(34)}$. As in the case of URP, children's BMI and parental perception about their children's body-weight status were the main determinants of ORP, but interestingly educational level of mothers was also found to be associated 
with ORP. Previous studies investigating the relationship between socio-economic factors (income, household size and level of education) and energy misreporting have shown mixed results or no association ${ }^{(22,25,26)}$. However, earlier studies have shown that low maternal education was associated with energy misreporting ${ }^{(26,35)}$. It is widely recognised that parents affect the family health awareness and play a direct role in shaping children's eating habits ${ }^{(36,37)}$. Moreover, they affect the consciousness concerning the potential problem of childhood overweight/obesity or underweight. Therefore, it could be hypothesised that parental perception regarding their children's body weight and diet may have influenced the children's conception towards more appropriate or acceptable food choices and dietary practices, as reflected in the accuracy of dietary data provided by them.

The validity of reported EI is often assessed by comparing EI with total energy expenditure. At present, the only way to obtain unbiased information on energy requirements in free-living settings is to use doubly labelled water as a biomarker $^{(3,4)}$. However, this technique is too expensive and impractical to be applied in large-scale epidemiological studies. Thus, the Goldberg approach was used alternatively, in order to identify energy misreporters ${ }^{(16)}$. There are a number of assumptions and limitations pertaining to the Goldberg cut-offs. The Goldberg equations assume that body weight is stable, which may not be the case for growing children in which the extra amount of energy is required for growth. Additionally, we cannot exclude the possibility that some plausible reporters might have been misclassified as over-reporters of EI because of rapid growth and actual high EI, as well as the fact that some of the children classified as under-reporters may be really under-eating or dieting ${ }^{(34)}$. Furthermore, there are important measurement issues that may influence reporting accuracy when children or adolescents are evaluated. These issues include difficulties in remembering the foods consumed, food recognition, and estimating portion size and frequency of consumption ${ }^{(6)}$. In the present study, we administered a validated self-reported, semi-quantitative picture-aid FFQ, which may have caused some of the aforementioned difficulties for children to complete, and especially for recalling the frequency of consumption over a long period of time. Hence, bedsides the intentional misreporting of EI, we cannot exclude that some random errors in dietary intake assessment might have occurred. Additionally, the studied age group of pre-adolescents is often characterised by irregular dietary patterns, eating occasions, and snacking frequencies, and therefore might be more prone to forgetting foods or drinks consumed ${ }^{(22,23)}$. Furthermore, we cannot exclude the possibility that the characteristics associated with biased energy reporting in children (i.e. breakfast skipping, less daily meals and snacks, body-weight dissatisfaction and concern) could be due to the strong association of URP and ORP with overweight/obesity, and the fact that these kinds of characteristics are frequently observed in overweight/ obesity children as well.

An important limitation of the present study is that the adopted cut-offs according to the Goldberg equation ${ }^{(16)}$ for the identification of URP and ORP children were applied by assuming an average PAL for all children. It has been proposed that considering individual PAL and, as a consequence, applying individual cut-off values depending on each child's PAL could improve sensitivity ${ }^{(38)}$. However, the Physical Activity Questionnaire ${ }^{(15)}$ that we used for the assessment of PAL has no definitive cut-offs for PAL classification, and therefore we could not categorise children. Setting an average PAL for the whole sample when objective measurements are lacking at the individual level has been proposed by other investigators ${ }^{(22)}$, while in the case of both children's and adults' studies assessing energy misreporting, average PAL values have been used previously $^{(21,39)}$. In addition, we did not follow the approach to use sex-specific cut-offs as done by some previous studies ${ }^{(22,25)}$. Therefore, we cannot exclude the possibility that this may have affected the observed sex difference found in the proportion of misreporters. Another important limitation is the low response rate of parental questionnaires, which may have introduced respondent bias from lower socio-economic groups that are more likely to be either non-responders in survey research, and overweight or obese ${ }^{(40)}$. However, in order to check for any bias regarding the data analyses, we compared BMI and the prevalence of misreporting of the two groups (i.e. children with and without parental information) and found no differences. Finally, although parental self-reported anthropometric values may have some errors, they are considered valid in identifying relationships in epidemiological studies ${ }^{(41)}$.

In conclusion, the present study confirms that the issue of URP and ORP in childhood populations is evident, can be quite serious, and may distort our understanding of the association between dietary factors and health status. Although there are no clear guidelines on how to use data obtained from energy misreporters in an epidemiological dataset (i.e. discarding or keeping them), there is a clear need to identify the characteristics of children who misreport. The most robust findings of the present study were the association between misreporting and BMI, and body-weight dissatisfaction. Finally, in both cases of URP and ORP, data accuracy was probably influenced by the need to report socially acceptable habits and patterns, as well as parental educational level and their perceptions regarding their children's body-weight status.

The present study was funded by the General Secretariat of Consumers-Greek Ministry of Development, the Hellenic Association of Food and Beverage Companies, Coca Cola Hellas, Coca-Cola Hellenic Bottling Company, Cereal Partners Hellas, FAGE SA, Unilever Hellas, Nestlé Hellas, Kraft Foods Hellas. The study was also funded by the European Union (European Social Fund) and Greek national funds through the Operational Program 'Education and Lifelong Learning' of the National Strategic Reference Framework (NSRF) - Research Funding Program: 'Heraclitus II. Investing in knowledge society through the European Social Fund'. The funders had no role in the design and analysis of the data or in the writing of this article.

\section{Acknowledgements}

The contributions of the authors are as follows: A. Z., D. B. P., G. R. and P. F. were responsible for the study design and the 
supervision of the field study; V. B., D. B. P. and P. F. were responsible for the statistical analysis; P. F., D. B. P., G. R. and A. Z. were responsible for the interpretation of the data. All authors carried out data management, contributed to database preparation and participated in the writing of the final version of the manuscript.

There are no conflicts of interest.

\section{References}

1. Roberts K \& Flaherty SJ (2010) Review of Dietary Assessment Methods in Public Health. Oxford: National Obesity Observatory.

2. Baily RL, Mitchell DC, Miller C, et al. (2007) Assessing the effect of underreporting energy intake on dietary patterns and weight status. J Am Diet Assoc 107, 64-71.

3. Black AE, Prentice AM, Goldberg GR, et al. (1993) Measurements of total energy expenditure provide insights into the validity of dietary measurements of energy intake. $J \mathrm{Am}$ Diet Assoc 93, 572-579.

4. Livingstone MB \& Black AE (2003) Markers of the validity of reported energy intake. J Nutr 133, 895S-920S.

5. Bornhorst C, Huybrechts I, Hebestreit A, et al. (2013) Diet-obesity associations in children: approaches to counteract attenuation caused by misreporting. Public Health Nutr 16, 256-266.

6. Livingstone MB, Robson PJ \& Wallace JMW (2004) Issues in dietary intake assessment of children and adolescents. Br J Nutr 92, S213-S222.

7. Forrestal SG (2011) Energy intake misreporting among children and adolescents: a literature review. Matern Child Nutr 7, 112-127.

8. Livingstone MB \& Robson PJ (2000) Measurement of dietary intake in children. Proc Nutr Soc 59, 279-293.

9. Farajian P, Risvas G, Karasouli K, et al. (2011) Very high childhood obesity prevalence and low adherence rates to the Mediterranean diet in Greek children: the GRECO study. Atherosclerosis 217, 525-530.

10. Cole TJ, Bellizzi MC, Flegal KM, et al. (2000) Establishing a standard definition for child overweight and obesity worldwide: international survey. BMJ 320, 1240-1243.

11. Farajian P, Karasouli K, Risvas G, et al. (2009) Repeatability and validity of a food frequency and dietary habits questionnaire in children. Circulation 119, e288.

12. Bountziouka V, Farajian P, Risvas G, et al. (2013) Development and validation of a semi-quantitative food frequency questionnaire for young school-aged children. Ann Nutr Metab 63, Suppl. 1, S1-S1960.

13. U.S. Department of Agriculture, Agricultural Research Service (2010) USDA National Nutrient Database for Standard Reference, Release 23. http://www.ars.usda.gov/ba/bhnrc/ ndl (accessed February 2011).

14. Trichopoulou A (2002) Composition Tables of Simple and Composite Foods. Athens, Greece: Parisianos.

15. Kowalski KC, Crocker PR \& Faulkner RA (1997) Validation of the physical activity questionnaire for older children. Pediatr Exerc Sci 9, 174-186.

16. Black A (2000) Critical evaluation of energy intake using the Goldberg cut-off for energy intake: basal metabolic rate A practical guide to its calculation, use and limitations. Int J Obes Relat Metab Disord 24, 1119-1130.

17. Schofield WN (1985) Predicting basal metabolic rate, new standards and review of previous work. Hum Nutr Clin Nutr 39C 5-41.

18. Goldberg GR, Black AE, Jebb SA, et al. (1991) Critical evaluation of energy intake data using fundamental principles of energy physiology. 1. Derivation of cut-off values to identify under-recording. Eur J Clin Nutr 45, 569-581.

19. World Health Organization (1997) Obesity: Preventing and Managing the Global Epidemic. Report of a WHO Consultation on Obesity. Technical Report Series no. 98.1. Geneva: WHO.

20. Panagiotakos DB, Pitsavos C, Arvaniti F, et al. (2005) Adherence to the Mediterranean food pattern predicts the prevalence of hypertension, hypercholesterolemia, diabetes and obesity, among healthy adults; the accuracy of the MedDietScore. Prev Med 44, 335-340.

21. Kobe H, Krzisnik C \& Mis NF (2012) Under- and over-reporting of energy intake in Slovenian adolescents. $J$ Nutr Educ Behav 44, 574-583.

22. Lioret S, Touvier M, Balin M, et al. (2011) Characteristics of energy under-reporting in children and adolescents. Br I Nutr 105, 1671-1680.

23. Rennie KL, Jebb SA, Wright A, et al. (2005) Secular trends in underreporting in young people. Br J Nutr 93, 241-247.

24. Ventura AK, Loken E, Mitchell DC, et al. (2006) Understanding reporting bias in the dietary recall data of 11-year-old girls. Obesity 14, 1073-1084.

25. Börnhorst C, Huybrechts I, Ahrens W, et al. (2013) Prevalence and determinants of misreporting among European children in proxy-reported $24 \mathrm{~h}$ dietary recalls. Br J Nutr 109, 1257-1265.

26. Murakami K, Miyake Y, Sasaki S, et al. (2012) Characteristics of under- and over-reporters of energy intake among Japanese children and adolescents: the Ryukyus Child Health study. Nutrition 28, 532-538.

27. Savage JS, Mitchell DC, Smiciklas-Wright H, et al. (2008) Plausible reports of energy intake may predict body mass index in pre-adolescent girls. J Am Diet Assoc 108, 131-135.

28. Bratteby LE, Sandhagen B, Fan H, et al. (1998) Total energy expenditure and physical activity as assessed by the doubly labeled water method in Swedish adolescents in whom energy intake was underestimated by 7 -d diet records. Am J Clin Nutr 67, 905-911.

29. Dietz WH (1994) Critical periods in childhood for the development of obesity. Am J Clin Nutr 59, 955-959.

30. Fisher JO, Johnson RK, Lindquist C, et al. (2000) Influence of body composition on the accuracy of reported energy intake in children. Obes Res 8, 597-603.

31. Risvas G, Panagiotakos DB, Chrysanthopoulou S, et al. (2008) Factors associated with food choices among Greek primary school students: a cluster analysis in the ELPYDES study. J Public Health (Oxf) 30, 266-273.

32. Huang TT, Roberts SB, Howarth NC, et al. (2005) Effect of screening out implausible energy intake reports on relationships between diet and BMI. Obes Res 13, 1205-1217.

33. McCrory MA, Hajduk CL \& Roberts SB (2002) Procedures for screening out inaccurate reports of dietary energy intake. Public Health Nutr 5, 873-882.

34. Vagstrand K, Lindroos AK \& Linne Y (2009) Characteristics of high and low energy reporting teenagers and their relationship to low energy reporting mothers. Public Health Nutr 12, 188-196.

35. Rangan AM, Flood VM \& Gill TP (2011) Misreporting of energy intake in the 2007 Australian Children's Survey: identification, characteristics and impact of misreporters. Nutrients 3, 186-199.

36. Reilly JJ, Armstrong J, Dorosty AR, et al. (2005) Early life risk factors for obesity in childhood: cohort study. BMJ $\mathbf{3 3 0}$, 1357-1364.

37. Wardle J, Carnell S, Haworth CM, et al. (2008) Evidence for a strong genetic influence on childhood adiposity despite 
the force of the obesogenic environment. Am J Clin Nutr 87, 398-404.

38. Black AE, Coward WA, Cole TJ, et al. (1996) Human energy expenditure in affluent societies: an analysis of 574 doubly-labelled water measurements. EurJ Clin Nutr 50, 72-92.

39. Streppel MT, de Vries JH, Meijboom S, et al. (2013) Relative validity of the food frequency questionnaire used to assess dietary intake in the Leiden Longevity Study. Nutr J 12, 75
40. Turell G, Patterson C, Oldenburg B, et al. (2006) The socioeconomic patterning of survey participation and non-response error in a multi-level study of food purchasing behaviour: area and individual level characteristics. Public Health Nutr 6, 181-189.

41. Spencer EA, Appleby PN, Davey GK, et al. (2002) Validity of self-reported height and weight in 4808 EPIC-Oxford participants. Public Health Nutr 5, 561-565. 